\title{
BENEFITS OF AGRICULTURAL WASTE FORM RICE PLANT 1: THE USE OF RICE WASTE TO PRODUCE ECO-FRIENDLY MATERIALS FOR DISPOSAL OF SOME ENVIRONMENTAL POLLUTANTS
}

Abd El Aziz, Gehan, H. and Shreen S. Ahmed

Soils, Water and Environment Research Institute, ARC, Giza, Egypt

\begin{abstract}
Available rice husk was used to provide a good alternative source of highly active silica for the synthesis environmentally-friendly mineral zeolites. In this study, recycling waste material (rice husk) to produce a valuable product and a high quality of silicon oxide was obtained. The obtained product characterized by X-ray powder diffraction. Furthermore, it could be successfully used as a filter for reduction of organic and inorganic pollutants from aquatic media. Data showed that zeolite product from rice husk ash has high ability to adsorption of organic pollutants (benzene and phenol) and inorganic pollutants ( $\mathrm{Cd}$ and $\mathrm{Pb}$ ) from aquatic media. It was found that adsorption percentage of $\mathrm{Cd}$ and $\mathrm{Pb}$ using $1.0 \mathrm{~g}$ synthetic zeolite being in the following accending order: $\mathrm{Pb} 2(55.0 \%)<\mathrm{Cd} 2(63.8 \%)<\mathrm{Pb} 1(69.9 \%)<\mathrm{Cd} 1(75.0 \%)$. However, the adsorption of organic pollutant using $1.0 \mathrm{~g}$ synthetic zeolite was in the following accending order: phenol2 $(54.0 \%)<$ benzen2 $(62.0 \%)<$ phenol1 $(87.8 \%)<$ benzen1 $(89.9 \%)$. Zeolite mineral product from rice husk ash represents a valid alternative to conventional approaches to pollutant compounds remediation, thanks to the good efficiency and to the low cost of the materials tested. Also, it is helping to reform and usefulness of rice waste.

Keywods: Rice husk; Zeolite; Seeding method; Ageing method; Highly active silica , water purification, waste utilization.
\end{abstract}

\section{INTRODUCTION}

Biomass is a renewable resource with great utilization due to environmental considerations and the increasing demands of energy worldwide. During rice refining processes, the husks are removed from grains. It is of little commercial value and because of its high silicon dioxide content; it is not useful to feed either human or animals. (Sharma et al.1988). Rice husk ash, a by-product of rice mill industry, is one of the alternative sources with high silica content and can be used for production of valuable materials and chemicals. The silica in rice husk ash is amorphous and transforms to crystalline silica when it is heated at high temperatures. Silica ash which is obtained from the complete burning of the husk constitutes 15$20 \%$ of the total weight of the rice husk. The silica ash produced contains more than $90 \% \mathrm{SiO}_{2}$ (Rahman et al., 2009). Rice husk can therefore provide a good alternative source of highly active silica for the synthesis of zeolite. There have been many researches encouraging the utilization of $\mathrm{SiO}_{2}$ from Rice husk ash for the synthesis of various types of zeolites and nanomaterials (Katsuki and Komarneni 2009 ; Witoon et al. 2009 ; and Ahmed and Adam 2010), the experimental results so far show its high potential for utilization, due to the differences in the nature of the Rice husk ash prepared and in the composition of the precursor gel. There are 
approximately 175 unique zeolite frameworks identified by the International Zeolites Association (2010) and over 40 naturally occurring zeolite frameworks are known. Zeolites are normally synthesized from aqueous basic aluminosilicate precursor gels under hydrothermal conditions (Jiao et al. 2008; Tsai et al. 2009 and Worathanakul et al. 2011). Zeolite can be naturally occurring or synthetic alluminosilicate of varying $\mathrm{Si} / \mathrm{Al}$ ratio and channel structures. It was estimated by Izni and Izni (2007) that over 40 different kinds of natural zeolites and over 100 synthetics are found in various part of the world. However; synthetics zeolites hold some key advantage over their natural analogs. According to Tagami, et al., (2001) zeolite can be manufactured in a uniform, pure form and require less time to manufacture in comparison to natural analogs which are rarely found in pure form and always contaminated to varying degree by other minerals such as Fe, quartz, amorphous. Innovation in the development of novel technologies to desalinate water is among the most exciting and promising. Recent advances suggest that many of the issues involving water quality could be resolved or greatly ameliorated using nanoparticles, nanofiltration or other products resulting from the development of technology. Aquifer and groundwater remediation are also critical issues, becoming more important as water supplies steadily decreases and demand continues to increase. Nitrobenzene has been widely adopted in the manufacture of dyes, plastic, pesticides, explosives, pharmaceuticals, and intermediates in chemical synthesis industries for years. A variety of possible treatment technologies such as adsorption, ozonation, and advanced oxidation processes have been taken into account for the purification of nitrobenzene contaminated water (Boyd et al. 2001). Phenols are considered one of the priority pollutants in wastewater, because they are harmful to organisms even at low concentrations. Many phenols have been classified as hazardous pollutants because of their potential toxicity to human health. Human consumption of phenol contaminant water can cause severe pain leading to damage of the capillaries ultimately causing death Uddin, et al (2007). Zeolite is used as molecular sieve. Species with kinetic diameter which make them too large to pass through a zeolite pores are effectively sieved. This sieve effect can be utilized to produce sharp separations of molecules by size and shapes. However, a particular affinity a species has for an internal zeolite cavity is electronic considerations. Strong electrostatic field within a zeolite cavity results in a very strong interaction with polar molecules such as water. Furthermore, Non polar molecules are also strongly absorbed due to the polarizing power of this electric field. Thus, excellent separations can be achieved by zeolites even when no steric hindrance occurs. Therefore, adsorption based on molecular sieve, electrostatic fields and polarity ability accounts for the considerable economic values of zeolite in adsorptive application (Rahman et al., 2012). Because cations are free to migrate in and out of zeolite structures, zeolites are often used to exchange their cations for those of surrounding fluids. The preference of a given zeolite among the available cations can be due to the ion sieving or due to a competition between the zeolite phase and aqueous phase for the cations that are present. Sodium zeolite A for example is among the world's most efficient 
removers of water hardness ions. This is its principle function as a detergent builder (Rahman et al., 2012). Zeolites make extremely active catalysts. Steric phenomena are very important in zeolite catalysis, and a new term "selective catalysis" was coined to describe these effects. Extremely selective reactions can be made to occur over zeolites, when certain products, reactants or transition states are kept from forming within the pores because of the size or shape. The current work aimed to: 1) Recycling rice husk for the production of metal zeolite. 2). Utilization the zeolite product as a filter for reduction of some environmental pollutants.

\section{MATERIALS AND METHODOLOGY}

Preparation of silica from rice husk ash: the rice husk was treated with $10 \%$ sulfuric acid for 24 hours for preliminary removing all impurities. The treated rice husk was washed thoroughly with distilled water, dried at $100^{\circ} \mathrm{C}$ and pyrolyzed in oxygen atmosphere at $500{ }^{\circ} \mathrm{C}$ for 6 hours. Zeolite was synthesized as according to Nik et al., (2007) and Rahman et al., (2009) with some modification. Zeolite was prepared by mixed two mixtures. The first mixture was silicate solution was prepared by mixing silica ash with $99 \%$ equivalent $\mathrm{NaOH}$ solution in the PTFE beaker and subsequently stirred and heated on the water bath at boiling $\mathrm{H}_{2} \mathrm{O}$ temperature. The second mixture was aluminum solution which prepared by adding $10.0 \mathrm{~mL} \mathrm{NaOH}$ solution to the $4.0 \mathrm{~g}$ sodium aluminum oxide $\mathrm{NaAlO}_{2}$ followed by stirring and heating until the mixture becomes it completely homogenized. The aluminate and silicate were then mixed in the PTFE beaker and stirred for two hours to achieve homogenization figure (1). Then the mixture was transferred to the Teflon bottle and capped for the ageing process to take place by leaving it at room temperature for $24 \mathrm{hrs}$.

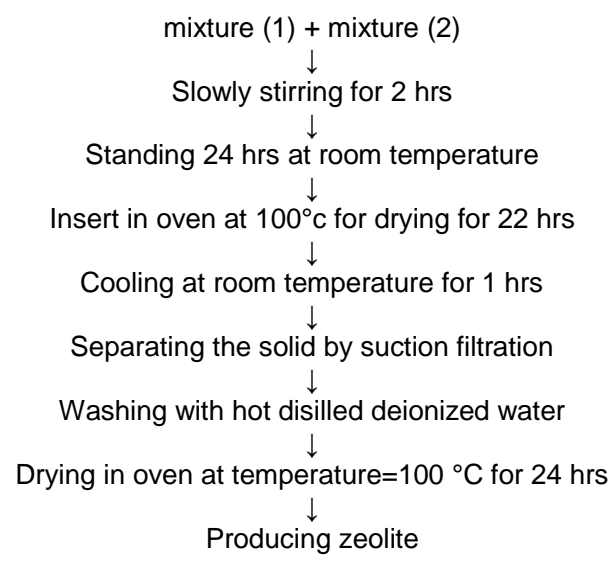

Fig 1 Preparation of Zeolite 


\section{X-Ray diffraction analysis of synthetic zeolite}

A Philip X-Ray diffraction equipment model XPert PRO with Monochromator, Cu-radiation $(\lambda=1.542 \AA \AA A)$ at $45 \mathrm{~K}$. V., 35 m.A. and scanning speed $0.02 \%$ sec were used. The reflection peaks between $20=2^{\circ}$ and $60^{\circ}$, corresponding spacing $(\mathrm{d}, \hat{A})$ and relative intensities $\left(\mathrm{l} / \mathrm{I}^{\circ}\right)$ were obtained. The diffraction charts and relative intensities were obtained and compared with ICDD files.

\section{Adsorption organic and inorganic pollutants experiments}

The obtained zeolite was tested as a filter for reduction of some environmental pollutants as inorganic $(\mathrm{Pb}$ or $\mathrm{Cd}$ ) and organic (Nitrobenzene or phenol).

\section{Metal ions solutions}

A stock solutions of heavy metals (lead or cadmium) ions with different concentrations ( 50 or $100 \mathrm{mg} \mathrm{L}^{-1}$ ) were prepared by dissolving an accurate quantity of $\mathrm{Pb}\left(\mathrm{NO}_{3}\right)_{2}$ or $\mathrm{CdSO}_{4}$ in deionized water. After preparation, the concentrations of metal were determined in each solution. On the other hand, synthetic zeolite was prepared and put in small cotton fiber bag with 0.5 or $1.0 \mathrm{~g}$ then each bag was individually soaked in $100 \mathrm{ml}$ of each heavy metal solution. The residual concentration of each heavy metal in solution was measured after soaking for $24 \mathrm{~h}$.

\section{Nitrobenzene and phenol Solutions}

This model pollutant was chosen for its toxicity. The effect of synthetic zeolite on the amount of removal of nitrobenzene and phenol solutions were obtained by contacting $100 \mathrm{ml}$ of nitrobenzene or phenol solution of initial concentration of $100 \mathrm{mg} / \mathrm{L}$ with weighed different amount $(0.5$ and $1.0 \mathrm{~g})$ of synthetic zeolite in stopper conical flask. The samples were then centrifuged and the concentrations in the supernatant nitrobenzene and phenol solutions were then analyzed as mentioned. Then a sample was collected, filtered through $0.45 \mathrm{~mm}$ filters and the residual aqueous nitrobenzene or phenol concentration was determined by spectrophotometry. Analytical methods

The final concentrations of each inorganic pollutant were measured. A metal ion was measured by using Inductively Coupled Plasma Spectrometry (Plasma JY Ultima). The residual nitrobenzene concentration was determined by spectrophotometry according to (Reungoat et al., 2007). The residual phenol concentration was determined by using the folin-ciocateu colorimetric method (Swain and Hillis, 1959). 
The removal efficiency and adsorption capacity were analyzed as the following Eqs:-

$\%$ removal $=[(\mathrm{Ci}-\mathrm{Cf}) / \mathrm{Ci}] \times 100$

where: $\mathrm{Ci}$ and $\mathrm{Cf}$ : are the initial and final metal concentrations $\left(\mathrm{mg} \mathrm{L}^{-1}\right)$, respectively.

\section{Statistical Analysis}

Data were statistically analyzed using Costat computer program according to procedures outlined by Snedecor and Cochran (1980).

\section{RESULT AND DISCUSSION}

\section{Characterization of Zeolite:}

Fig. 2 shows the images of obtained zeolite from rice husk ash. The original (Figure 2A) zeolite particles typically had spherical shapesat different sizes, with a smooth surface made of an aluminosilicate glass phase. Upon formation of zeolite, (Figure 2B) the surface became rough, indicating the deposition of clusters of zeolite crystals. Diffractogram of XRD and morphology are given in the Table 1 and illustrated in Figure 3. Chemical Formula of Na-zeolite prepartion are given in Table 2. The characteristic XRD peaks of synthetic zeaolite at $2 \theta: 2^{\circ}$ and $60^{\circ}$ are quite consistent with the reference sample indicating that a major compound is formed in this work was a pure crystalline zeolite (Gismondine) with chemical formula $\mathrm{Ca} \mathrm{Al}_{2} \mathrm{Si}_{2}$ $\mathrm{O}_{8} \cdot 4 \mathrm{H}_{2} \mathrm{O}$.

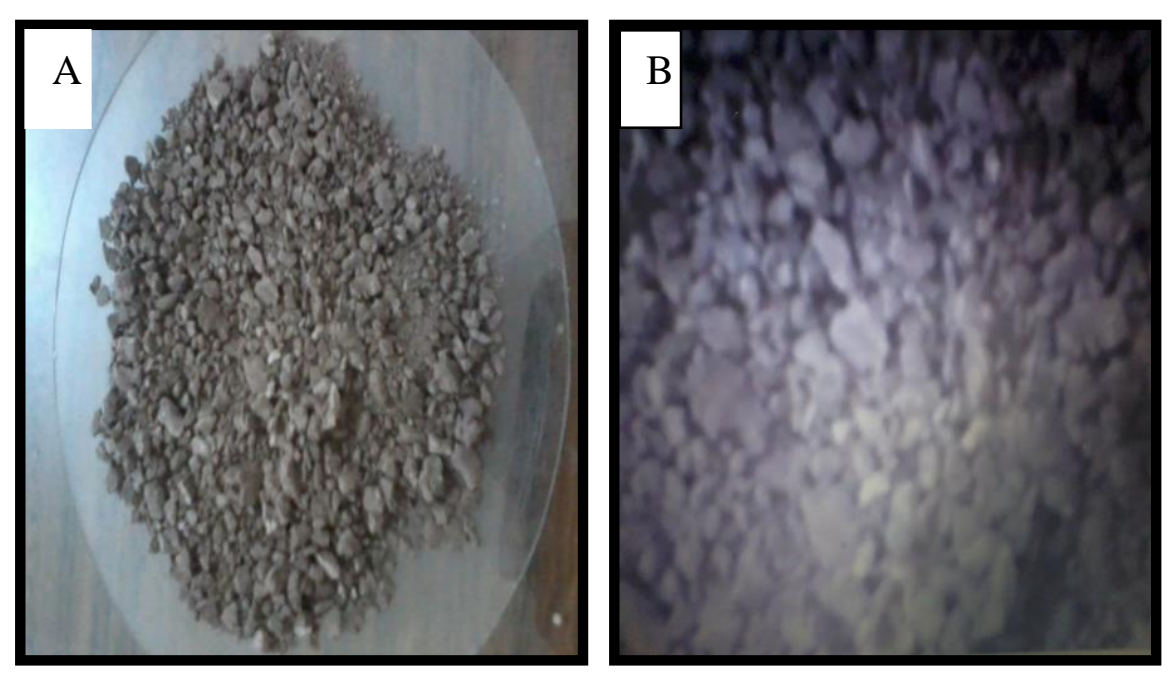

Fig. 2: Images of obtained zeolite 


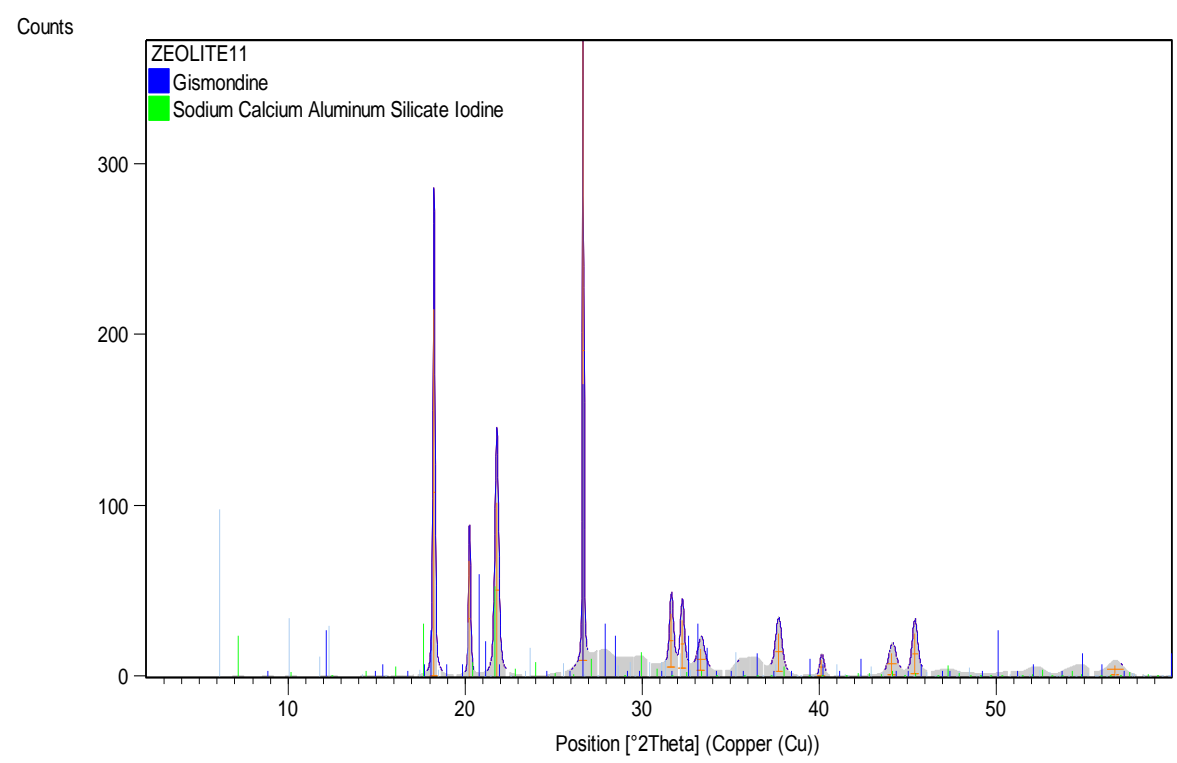

Fig. 3: XRD peak of synthetic zeolite

Table 1: Chemical Formula of zeolite prepartion

\begin{tabular}{|c|c|c|c|c|c|c|}
\hline Visible & Ref. Code & Score & $\begin{array}{c}\text { Compound } \\
\text { Name }\end{array}$ & $\begin{array}{c}\text { Displaceme } \\
\text { nt [ [02Th.] }\end{array}$ & $\begin{array}{c}\text { Scale } \\
\text { Factor }\end{array}$ & Chemical Formula \\
\hline * & 00-020-0452 & 11 & $\begin{array}{c}\text { (Gismondine) } \\
\text { Calcium } \\
\text { Aluminum } \\
\text { Silicate } \\
\text { Hydrate }\end{array}$ & 0.000 & 0.460 & $\mathrm{Ca} \mathrm{Al}_{2} \mathrm{Si}_{2} \mathrm{O}_{8} \cdot 4 \mathrm{H}_{2} \mathrm{O}$ \\
\hline * & 01-072-0084 & 5 & $\begin{array}{l}\text { Sodium } \\
\text { Calcium } \\
\text { Aluminum } \\
\text { Silicate } \\
\text { lodine }\end{array}$ & 0.000 & 0.141 & $\begin{array}{c}\mathrm{Na}_{4} \mathrm{Ca}_{4} \mathrm{Si}_{12} \mathrm{Al}_{12} \mathrm{O}_{48} \\
\left(\mathrm{I}_{2}\right) 5.52\end{array}$ \\
\hline
\end{tabular}

\section{Adsorption organic and inorganic pollutants experiments}

Data of residual organic pollutant (phenol and benzene) are presented in Table 2. Data showed that, the previously synthesized zeolite with different weights decreased concentrations (100 and 500 ppm) of organic pollutants (phenol and nitrobenzene). Percentages of residual benzene reached 20.8 and $50 \%$ when $0.5 \mathrm{~g}$ synthetic zeolite was used, respectively. The same results observed with $1.0 \mathrm{~g}$ of synthetic zeolite per $100 \mathrm{ml}$ of 100 and $500 \mathrm{ppm}$ benzene solution. Percentages of residual benzene reached 10.1 and $38 \%$, respectively. Regarding the phenol, when $0.5 \mathrm{~g}$ of synthetic zeolite was used, Percentages of residual phenol reached 43.6 and $62 \%$, respectively. The percentages of residual phenol reached 12.2 and $46 \%$ when $0.5 \mathrm{~g}$ synthetic zeolite was used, respectively. Consequently, 
statistical analysis for the comparison of efficacies of zeolite at different concentration of phenol and benzene were significantly different at $p \leq 0.05$. From this analysis, it is evident that the adsorption of organic pollutant using synthetic zeolite with $0.5 \mathrm{~g}$ was in the following acending order: phenol2 $(38.0 \%)<$ benzen2 $(50.0 \%)<$ phenol1 $(56.4 \%)<$ benzen1 $(79.2 \%)$. The adsorption of organic pollutant using synthetic zeolite with $1.0 \mathrm{~g}$ followed the same behavior with different values: phenol2 $(54.0 \%)<$ benzen2 $(62.0 \%)<$ phenol1 $(87.8 \%)$ < benzen1 (89.9\%).

Data of residual inorganic pollutants $(\mathrm{Cd}$ and $\mathrm{Pb})$ are presented in Table 3. Data showed that synthetic zeolite under investigation with different weights $(0.5$ and $1.0 \mathrm{~g})$ decreased heavy metals concentration. Adsorption percentage of $\mathrm{Cd}$ and $\mathrm{Pb}$ using synthetic zeolite with $0.5 \mathrm{~g}$ was in the following accending order: Pb2 $(43.27 \%)<\mathrm{Cd} 2(53.3 \%)<\mathrm{Cd} 1(62.0 \%)<$ $\mathrm{Pb} 1(66.1 \%)$. Also results showed that $1.0 \mathrm{~g}$ of synthetic zeolite decreased heavy metals concentration from 50 and $500 \mathrm{ppm}$ initial concentration. Adsorption percentage of $\mathrm{Cd}$ and $\mathrm{Pb}$ using synthetic zeolite with $1.0 \mathrm{~g}$ was in the following accending order: Pb2 $(55.0 \%)<\mathrm{Cd} 2(63.8 \%)<\mathrm{Pb} 1(69.9 \%)<$ Cd1 (75.0\%).

Generally, the percentage removal of the each pollutant increased with increasing adsorbent dosage. Removal of both pollutants (organic and inorganic) using different weights of zeolite was observed in the following accending order: $0.5 \mathrm{~g}<1.0 \mathrm{~g}$ per $100 \mathrm{ml}$ of each pollutant solution $(50 \mathrm{ppm}$ $\mathrm{Cd}, 500 \mathrm{ppm} \mathrm{Cd}, 50 \mathrm{ppm} \mathrm{Pb}, 500 \mathrm{ppm} \mathrm{Pb}, 100$ ppm benzene, 500 ppm benzene, $100 \mathrm{ppm}$ phenol, and $500 \mathrm{ppm}$ phenol). This can be attributed to increased adsorbent surface area and availability of more adsorption sites resulting from the increase adsorbent dosage as mentioned by Saravanakumar and Kumar (2012). Many researchers, (Brett et al., 2003, and Savage and Diallo, 2005) reported the successful use of synthetic Zeolite to remove $\mathrm{Cr}(\mathrm{III}), \mathrm{Ni}(\mathrm{II}), \mathrm{Zn}(\mathrm{II}), \mathrm{Cu}(\mathrm{II})$ and $\mathrm{Cd}(\mathrm{II})$ from metals electroplating wastewater. zeolite is an effective sorbents and ion-exchange media for metal ions which was evaluated as an ion exchange media for the removal of heavy metals from wastewater. Synthetic zeolites are interesting from the point view of their usability as efficient adsorbents for removal of many pollutants from the environment (Bardakçi and Kaya, 2009).

Table 2: Residual and adsorption\% benzene and phenol from polluted water by Synthetic zeolite

\begin{tabular}{|l|c|c|c|c|c|}
\hline \multirow{2}{*}{$\begin{array}{l}\text { Organic } \\
\text { pollutants }\end{array}$} & \multirow{2}{*}{$\begin{array}{c}\text { Initial } \\
\text { concentration } \\
\text { (ppm) }\end{array}$} & \multicolumn{4}{|c|}{ Synthetic zeolite } \\
\cline { 3 - 6 } & & \multicolumn{2}{|c|}{$\mathbf{0 . 5} \mathbf{g}$} & \multicolumn{2}{|c|}{$\mathbf{1 . 0}$ g } \\
\hline Benzene1 & 100 & 20.8 & $79.20^{\mathrm{A}}$ & 10.1 & $89.87^{\mathrm{A}}$ \\
\hline Benzene2 & 500 & 250 & $50.00^{\mathrm{C}}$ & 190 & $62.00^{\mathrm{C}}$ \\
\hline Phenol1 & 100 & 43.6 & $56.43^{\mathrm{B}}$ & 12.2 & $87.80^{\mathrm{B}}$ \\
\hline Phenol2 & 500 & 310 & $38.00^{\mathrm{D}}$ & 230 & $54.00^{\mathrm{D}}$ \\
\hline LSD & & & 2.369 & & 1.307 \\
\hline
\end{tabular}


Table 3: Residual and adsorption\% cadmium and lead from metal solution by Synthetic zeolite

\begin{tabular}{|c|c|c|c|c|c|}
\hline \multirow{3}{*}{ Metal } & \multirow{3}{*}{$\begin{array}{c}\text { Initial } \\
\text { concentration } \\
(p p m)\end{array}$} & \multicolumn{4}{|c|}{ Synthetic zeolite } \\
\hline & & \multicolumn{2}{|c|}{$0.5 \mathrm{~g}$} & \multicolumn{2}{|r|}{$1.0 \mathrm{~g}$} \\
\hline & & residual & Adsorption \% & residual & Adsorption\% \\
\hline Cd1 & 50 & 16.35 & $67.00^{A}$ & 12.5 & $75.00^{A}$ \\
\hline $\mathrm{Cd} 2$ & 500 & 232.5 & $53.03^{C}$ & 180.0 & $63.83^{C}$ \\
\hline $\mathrm{Pb} 1$ & 50 & 17.0 & $66.10^{\mathrm{B}}$ & 15.0 & $69.97^{\mathrm{B}}$ \\
\hline $\mathrm{Pb} 2$ & 500 & 282.5 & $43.27^{D}$ & 225.0 & $55.03^{\mathrm{V}}$ \\
\hline LSD & & & 0.3937 & & 0.2411 \\
\hline
\end{tabular}

\section{CONCLUSIONS}

\section{The results obtained showed the following:}

- Recycling waste material (rice husk) to produce a valuable product and a high quality of silicon oxide was obtained.

- Production of zeolite from rice husk ash has been found to be significantly improved the adsorption and ion exchange capability towards organic pollutants (benzene and phenol) and inorganic pollutants $(\mathrm{Cd}$ and $\mathrm{Pb})$.

- Production of zeolite from rice husk ash represents a valid alternative to conventional approaches to pollutant compounds remediation. Also, it is helping to reform and usefulness of rice waste.

\section{REFFERENCE}

Ahmed, A.E. and Adam, F. (2010). The catalytic performances of silica supported aluminum, gallium and indium for the tert-butylation of aromatics, J. Sol-Gel Sci. Technol., 54: 9-18.

Bardakçi, B. and Kaya, N. (2009). FT-IR Spectroscopic Study of Triethyl Phospate Adsorption on FAU type zeolites. Asian J. Chem. 21(6):49144918.

Boyd, S.A.; Sheng, G.Y.; Teppen, B.J. and Johnston, C.T. (2001). Mechanisms for the Adsorption of Substituted Nitrobenzenes by Smectite Clays, Environ. Sci. Technol.35 (2001) 4227-4234.

Brett, A.H.; Hunting, W.; Norbeck, J.M and Yan, Y. (2003). Controlling size and Yeeld of zeolite $Y$ nanocrystals using Tetramethyammonium bromide, Micro. Meso. Materi., 59: 13-16.

International Zeolite Association Database of Zeolite Structures, http:/ /www.iza structure.org/databases, 2008 (Accessed 10 May 2010).

Izni, E. and Izni, A. (2007). Dielectric behavior of catalyst zeolite $\mathrm{Na}-\mathrm{Y}$,. Turkey Journal of chemistry, 31: 523-530.

Jiao, G.F.; Min, P. and Chen, B.H. (2008). Theoretical study of formation mechanism of aluminosilicate in the synthesis of zeolites, Struct. Chem., 19: 481-487. 
Katsuki, H. and Komarneni, S. (2009). Synthesis of Na-A and/or Na-X zeolite/porous carbon composites from carbonized rice husk, J. Solid State Chem., 182: 1749-1753.

Nik, A.; Nik, M. and Alias M. Y. (2007). Removal of Cr (III) from aqueous solution using Zeolite $\mathrm{Na}-\mathrm{Y}$ Prepared from Rice husks ash, The Malaysian Journal of analytical science, 11(1): 76-83.

Rahman, M. M.; Hasnida, N.; and Wan Nik, W. B. (2009). Preparation of Zeolite Y Using Local Raw Material Rice Husk as a Silica Source, J. Sci. Res., 1(1): 285-291.

Rahman, M.M.;. Awang, M.B. and Yusof, A.M.(2012). Preparation Characterization and Application of Zeolite-Y (Na-Y) for Water Filtration, Australian Journal of Basic and Applied Sciences, 6(1):50-54.

Reungoat, J.; Pic, J. S. and Debellefontaine, H. (2007). Adsorption of Nitrobenzene from Water onto High Silica Zeolites and Regeneration by Ozone. Separation Science And Technology -New York- Marcel Dekker-; 42, 7; 1447-1463

Saravanakumar, K. and Kumar, A. ( 2012). Treatment of Aqueous Solution of Phenol by Adsorption on Sodium Zeolite. Research Journal of Pharmaceutical, Biological and Chemical Sciences, 2 (4): 18-26.

Savage, N. and Diallo,M.S.(2005).Nano materials and water purification: opportunities and challenges." Journal Nano particle research,7:331342.

Sharma, S. K.; Sharma, C. M. and Shakor, I. S. (1988). Effect of industrial organic wastes and lantana incorporation on soil properties and yield of rice. Indian J. of Agronomy. 33: 225-226.

Snedecor, G.W. and Cochran, W.G. (1980). Statistical Method. 7th Ed., lowa State Univ. Press, Ames, lowa, USA.

Swain, T. and Hillis, W. E. (1959). The quantitative analysis of phenolic constituents. J. Sci. Food Agric., 10:63-69.

Tsai, W.T.; Hsien, K.J.; and Hsu, H.C. (2009). Preparation and characterization of a novel zeolite using hydrothermal synthesis in a stirred reactor, J. Sol-Gel Sci. Techn., 2009; 49: 261-267.

Tagami, L.; Andreo, O.; Santos, A.; Falabela, E.A.; guiar, S.; Arroy, P.A.; Simeos M.A.; and Barros, D. (2001). Na-Y and $\mathrm{Cr}-\mathrm{Y}$ zeolite ion exchange, Thermodynamics. Acta scientiarum, 23(6): 1351-1357.

Uddin, M. T.; Islam, M. S. and Abedin M. Z. (2007). Adsorption of Phenol From Aqueous Solution By Water Hyacinth Ash. Journal of Engineering and Applied Sciences., 2 (2):11-17.

Witoon, T.; Chareonpanich, M.; and Limtrakul, J. (2009). Effect of acidity on the formation of silica-chitosan hybrid materials and thermal conductive property, J. Sol-Gel Sci. Technol., 51: 146-152.

Worathanakul, P.; Trisuwan, D.; Phatruk, A. and Kongkachuichay, P. (2011). Effect of sol-gel synthesis parameters and $\mathrm{Cu}$ loading on the physicochemical properties of a new SUZ-4 zeolite, Colloid. Surface. A, 377: 187-194. 


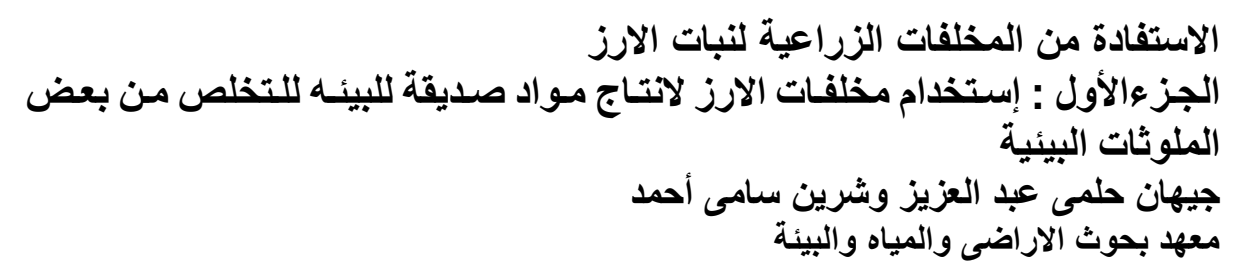

تم استخدام قشر الأرز المتاح لتوفير مصدر بديل جيد من السيليكا النشطة للغايـة لانتاج

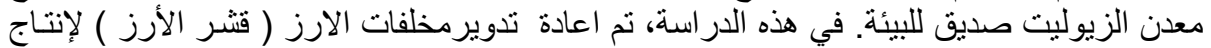

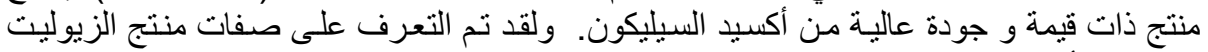

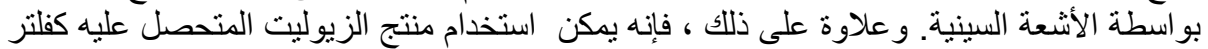

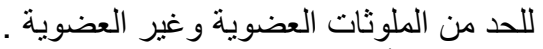

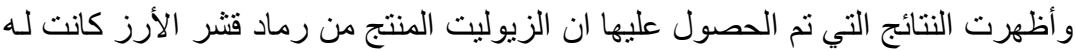

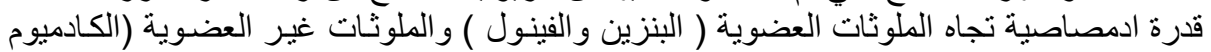

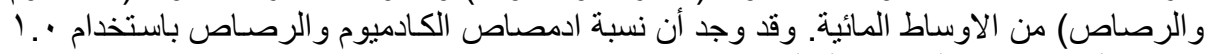

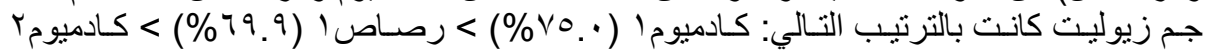

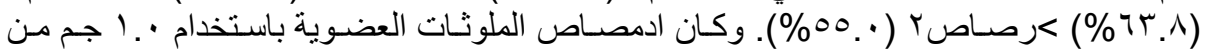

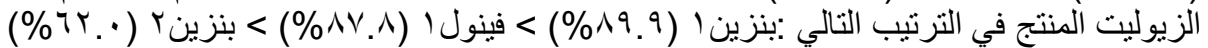

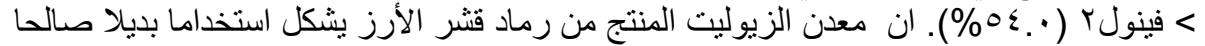

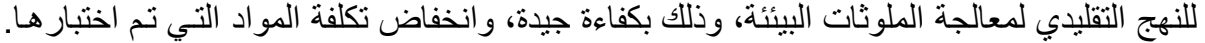
و المساعده فى التخلص من مخلفات الأرز و إعادة إستخدامها بكفاءة لصالح الصالح البيئة.

كلية الزراعة - جامعة المنصورة مركز البحوث الزراعية
قام بتحكيم البحث

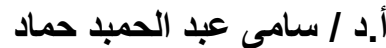

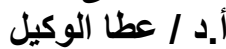

